\title{
AS DISPUTAS PELOS CONTORNOS DO ACESSO À EDUCAÇÃO SUPERIOR NA CONSTITUIÇÃO DE 1988: capacidade para quem? // Maurício Buosi Lemes $^{1}$ e Fabiana Cristina Severi²
}

\author{
Palavras-chave \\ meritocracia / democracia racial / Constituição \\ radical / sociedade aberta dos intérpretes da \\ Constituição / políticas afirmativas
}

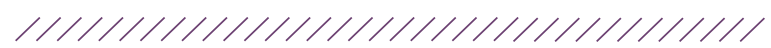

\section{Sumário}

1 Introdução

2 Aspectos metodológicos

3 Marco teórico-conceitual: Constituição radical e sociedade aberta dos intérpretes da Constituição

4 O processo constituinte de 1987/88 e a conformação de sentidos para o direito à educação superior na Constituição Federal de 1988

5 Percepções de estudantes de ensino médio de escola pública sobre vestibular, ações afirmativas, universidade pública e direito à educação

6 Considerações finais

7 Referências

\section{Resumo}

Nosso objetivo consiste em analisar a problemática da democratização do acesso às instituições públicas de educação superior no Brasil, com foco em algumas disputas do processo constituinte de 1987/88 e nas percepções de estudantes de ensino médio de escola pública sobre vestibular, ações afirmativas, universidade pública e direito à educação. Buscamos compreender essas narrativas a partir do marco teórico-conceitual de Constituição radical e de sociedade aberta dos intérpretes da Constituição. Enquanto procedimento metodológico, realizamos uma pesquisa sociojurídica empírica, de cunho qualitativo, que teve como fontes de coleta de dados alguns fragmentos de atas das audiências públicas realizadas pela Subcomissão dos $\mathrm{Ne}$ gros e da Educação no âmbito da Assembleia Nacional Constituinte de $1987 / 88$, e entrevistas semiestruturadas com estudantes. Para a interpretação dos dados obtidos, procuramos utilizar as ferramentas da Análise de Conteúdo. Em termos de tensão entre poder constituinte e poder constituído, diferentes narrativas estiveram em conflito pela significação social do direito à educação e do acesso ao ensino superior na Constituinte de 1987/88. Embora a narrativa do mérito individual tenha se tornado hegemônica, a linguagem dos direitos expressa pela Constituição Federal de 1988 e o alargamento do círculo de seus intérpretes têm possibilitado novos campos semânticos para que os movimentos negro, de luta pelo direito à educação e estudantes de ensino médio público reivindiquem uma gramática jurídica compatível com as suas experiências sociais.

\footnotetext{
1 Graduado em Direito pela Faculdade de Direito de Ribeirão Preto da Universidade de São Paulo (FDRP/USP). Atualmente, é mestrando vinculado ao Programa de Pós-Graduação em Direito da FDRP/ USP, desenvolvendo projeto de pesquisa sobre acesso à justiça, democratização do sistema de justiça brasileiro, participação popular e Defensoria Pública, com fomento da Fundação de Amparo à Pesquisa do Estado de São Paulo (FAPESP).

2 Professora Associada do Departamento de Direito Público e do Programa de Mestrado em Direito da Faculdade de Direito de Ribeirão Preto da Universidade de São Paulo (FDRP/USP). Livre Docente em Direitos Humanos pela FDRP/USP (2017).
} 


\section{CAPACITY TO WHOM? The disputes for the outlines of access to higher education in 1988's Constitution // Maurício Buosi Lemes and}

\section{Fabiana Cristina Severi}

\section{Keywords}

meritocracy / racial democracy / radical constitution/ open society of the constitution interpreters /

affirmative policies

HIIIIIIIIIIIIIIIIIIIIIIIIIIIIIIIII

\section{Abstract}

Our objective is to analyze the problem of democratizing the access to higher education public institutions in Brazil, focusing on some disputes of the constituent process of $1987 / 88$, as well as on public high school students' perceptions on universities entrance exams, affirmative actions, public university and the right to education. We seek to understand these narratives in light of the Constitution interpreters' conceptions about radical Constitution, as well as their conceptions about open society. As for the method, we performed an empirical qualitative sociojuridic research, which used as sources a few fragments of records of public audiences done by the Subcomissão dos Negros e da Educação (Black People and Education Subcommittee) during the Constituent National Assembly in $1987 / 1988$, as well as semi-structured interviews with students. In order to interpret the obtained data, we used the tools of the Content Analysis Method. In terms of tensions between constituent power and constituted power, during the constituent process of $1987 / 88$, different narratives have been in conflict for the social significance of the right to education and the access to higher education. Although the narrative of individual merit has become hegemonic, the language of rights expressed in 1988's Constitution and the broadening of its circle of interpreters have enabled new semantic fields for the black, education, and high public school movements to claim a juridical grammar compatible with their social experiences. 


\section{Introdução}

O presente texto é proveniente de nosso trabalho de pesquisa ${ }^{3}$ em que buscamos analisar alguns processos histórico-sociais recentes de democratização do Estado e da sociedade brasileira, com foco nas reivindicações do movimento negro e de outros atores sociais por políticas afirmativas de cotas nas instituições públicas de educação superior.

A Constituição Federal de 1988 (CF/88) instituiu o Estado Democrático de Direito enquanto horizonte sociopolítico em permanente disputa. Seu texto materializa, no campo jurídico, as relações de poder existentes na sociedade brasileira e presentes na Assembleia Nacional Constituinte de 1987/88, responsáveis por um complexo processo de conflitos e de negociações em torno de projetos constitucionais conservador e democrático.

Essa Constituição legislou sobre uma série de diferenças sociais em razão da pressão intensa da sociedade civil organizada sobre a Assembleia Nacional Constituinte, o que resultou em um texto extenso, fruto de ampla participação social. A construção de uma sociedade livre, justa e solidária, a erradicação da pobreza e da marginalização, a redução das desigualdades sociais e a promoção do bem de todos e de todas, sem preconceitos de origem, raça, sexo, cor, idade e quaisquer outras formas de discriminação, são alguns dos objetivos fundamentais da República brasileira.

Em matéria de direito à educação, a $\mathrm{CF} / 88$ tratou-o em seus diferentes níveis e modalidades e abordou os mais diversos conteúdos. Em sintonia com o momento de abertura política, a tônica do texto é a de uma "Constituição cidadã", expressa principalmente nos artigos que tratam da concepção, dos princípios e dos deveres do Estado no campo da educação, propondo

3 A pesquisa contou com fomento da Fundação de Amparo à Pesquisa do Estado de São Paulo - FAPESP entre 2015 e 2016 (processo $n^{\circ}$ 2015/07870-6). Agradecemos à Professora Doutora Debora Cristina Piotto, da Faculdade de Filosofia, Ciências e Letras de Ribeirão Preto da Universidade de São Paulo (FFCLRP/USP), e ao Professor Doutor Caio Gracco Pinheiro Dias, da Faculdade de Direito de Ribeirão Preto da Universidade de São Paulo (FDRP/USP), pelas relevantes contribuições apresentadas no momento de defesa do nosso trabalho. Agradecemos também à Tharuell Lima Kahwage, à Gabriela de Oliveira Leal, à Danieli Rocha Chiuzuli e à Inara Flora Cipriano Firmino pela leitura e revisão do texto. a inclusão de sujeitos historicamente excluídos desse direito, através do princípio de igualdade de condições para o acesso e a permanência na escola (Vieira, 2007).

No tocante ao acesso à educação superior, o artigo 208, inciso V, da CF/88 dispõe que "O dever do Estado com a educação será efetivado mediante a garantia de acesso aos níveis mais elevados do ensino, da pesquisa e da criação artística, segundo a capacidade de cada um". Esse mesmo critério foi introduzido posteriormente no artigo $4^{\circ}$, inciso $V$, da Lei de Diretrizes e Bases da Educação Nacional (LDB - Lei n 9.394, de 20 de dezembro de 1996).

A universidade brasileira permanece um espaço não universalizado cujo ingresso está legalmente condicionado às capacidades individuais. Os indicadores sociais de acesso a esse nível de ensino têm demonstrado que, ao longo da trajetória escolar, ocorre o embranquecimento e elitização das turmas: há uma forte tendência de maior presença de estudantes brancos(as) e de classe média/alta e de menor número de negros(as) e de classes sociais baixas à medida que a escolaridade avança (Pinto, 2003).

A longa e difícil caminhada que um(a) estudante faz desde que ingressa no primeiro ano do ensino fundamental até o acesso à educação superior tem funcionado como um filtro étnico-racial (que exclui os(as) afrodescendentes e indígenas) e socioeconômico (que barra os(as) estudantes de baixa renda). Assim, a utilização do termo "capacidade" pelo texto constitucional e infraconstitucional é ambígua, visto que existem negros, negras e estudantes de baixa renda "capazes" a quem é negado o exercício do direito fundamental à educação (Pinto, 2003; Pinto, 2004).

A ação política do movimento negro e de outros setores sociais vem denunciando um contexto de flagrantes desigualdades em que se realiza o exame vestibular no Brasil e explicitando a necessidade de avançarmos no debate acerca da democratização da universidade, no sentido de torná-la um bem ao qual todos e todas têm o direito de aspirar.

Se o ensino superior é diferente da educação básica ou de outros direitos sociais necessariamente assegurados a todos os cidadãos e cidadãs, precisando estabelecer critérios e normas de seleção que visem garantir 
um corpo discente qualificado, essa constatação não autoriza a monopolização da universidade por grupos social e racialmente dominantes. Vem se tornando cada vez mais evidente o dever do Estado e das instituições de ensino superior, sobretudo as universidades públicas, em contemplar, de forma justa e igualitária, as legítimas aspirações de estudantes de todas as raças e classes sociais (Feres Júnior, Daflon, 2014).

Nesse artigo, buscamos resgatar e compreender alguns aspectos dos debates ocorridos no processo constituinte que resultou na $\mathrm{CF} / 88$ a partir da concepção de Constituição radical de Chueiri (2013) e de sociedade aberta dos intérpretes da Constituição de Haberle (1997), de modo a explicitar certas disputas pelo sentido e alcance do direito à educação e do acesso ao ensino superior. À luz dessas memórias e narrativas em tensão, propomo-nos a analisar as percepções de estudantes de ensino médio de uma escola pública em Ribeirão Preto - SP acerca das relações entre vestibular, ações afirmativas, universidade pública e direito à educação, com vistas ao entendimento da maneira como as discussões sobre políticas de cotas permeiam a construção de suas subjetividades e de suas interpretações sobre os direitos em questão.

\section{$2 \quad$ Aspectos metodológicos}

Realizamos uma pesquisa sociojurídica empírica, de cunho qualitativo, que teve como fontes de coleta de dados: 1) alguns fragmentos de atas de audiências públicas de duas Subcomissões temáticas que compuseram a Assembleia Nacional Constituinte de 1987/88: na Comissão da Ordem Social, a Subcomissão dos Negros, Populações Indígenas, Pessoas Deficientes e Minorias ${ }^{4}$ e, na Comissão da Família, da Educação, Cultura e Esportes, da Ciência e Tecnologia e da Comunicação, a Subcomissão da Educação, Cultura e Esportes ${ }^{5}$; e 2) as entrevistas semiestruturadas com estudantes de ensino médio de escola pública em Ribeirão Preto - SP, a partir das quais organizamos em categorias os dados obtidos: as percepções do(a) estudante sobre vestibular, ações afirmativas, universidade pú-

4 Na sequência do texto, por economia e fluidez da leitura, faremos referência a essa Subcomissão apenas como Subcomissão dos Negros. $5 \mathrm{Na}$ sequência do texto, por economia e fluidez da leitura, faremos referência a essa Subcomissão apenas como Subcomissão da Educação. blica e direito à educação. Essas categorias estavam presentes na estruturação do roteiro de entrevista.

Em 2009, a Consultoria Legislativa da Câmara dos Deputados, com a colaboração do Centro de Documentação e Informação, publicou uma reunião de relatos das audiências públicas promovidas pelas Subcomissões da Assembleia Nacional Constituinte. Trata-se da obra: Audiências públicas na Assembleia Nacional Constituinte: a sociedade na tribuna, de organização de Ana Luiza Backes, Débora Bithiah de Azevedo e José Cordeiro de Araújo. A partir das indicações desses registros históricos, reunimos, nesse artigo, trechos significativos atinentes à nossa problemática de investigação.

As Subcomissões dos Negros e da Educação foram escolhidas por conta de sua pertinência com os eixos centrais de nossa pesquisa, desigualdades étnico-raciais e acesso ao ensino superior, e porque imaginamos que nelas tenham se dado os debates e conflitos que conformam os sentidos sobre os direitos em questão.

As entrevistas foram feitas com estudantes de terceiro ano de ensino médio de escola pública por estarem entre os principais destinatários das políticas de cotas e na etapa escolar propícia para prestarem o exame vestibular. Após a aprovação do Comitê de Ética em Pesquisa e a elaboração do roteiro, realizamos nove entrevistas entre abril e junho de 2016, sendo três em cada período de aulas da escola (manhã, tarde e noite). Nesse texto, buscamos apresentar e discutir as falas dos(as) estudantes que entendemos mais representativas do material empírico coletado.

Todas as entrevistas foram gravadas e integralmente transcritas após a sua realização. Os nomes dos estudantes foram substituídos por fictícios, a fim de mantermos o anonimato. Com a coleta e a organização desse material, adotamos, em nosso estudo, para a interpretação dos dados, os referenciais da análise de conteúdo (Triviños, 2011).

\section{Marco teórico-conceitual: Constituição radical e sociedade aberta dos intérpretes da Constituição}

Na sociedade brasileira, profundamente desigual e em que a Constituição traz a promessa de igualdade, 
os diferentes grupos e movimentos sociais em situação de opressão vêm comparando sua condição com a dos outros e formulando, na esfera pública, sua insatisfação e suas percepções de desigualdades sob a forma de reivindicação por direitos. A renovação e a legitimação da democracia e da Constituição dependem de demandas constantes por novos direitos por parte da sociedade, capazes de questionar o status quo. Um direito democrático só é possível desde que haja uma sociedade civil ativa que produza constantemente novas demandas, deixando a condição de massa governada e passando a viver a vida política de forma plena, movida por uma autodeterminação consciente e livre (Rodriguez, 2013).

No nosso estudo, buscamos problematizar a positivação da expressão "capacidade de cada um" no texto constitucional, enquanto critério meritocrático para acesso à educação superior, através da compreensão das tensões entre poder constituinte e Constituição. Associamos a CF/88 ao conceito de Constituição radical, uma vez que essa Constituição tem viabilizado uma mediação para a ação política, à medida que não se deixa reduzir ao poder constituído, mas nela retém o poder constituinte e, dessa forma, constitui, radicalmente, a comunidade política (Chueiri, 2013).

Uma Constituição radical não se limita aos mecanismos liberais de mútua negociação entre os poderes constituídos, mas abrange a possibilidade de ser instrumento da política democrática. Os direitos estão na Constituição, conforme ela permite a constante reinvenção e demandas por novos direitos, através da tensão, do conflito, entre os poderes constituídos e o poder constituinte. O constitucionalismo não pode estar limitado à ideia de Constituição (passado), descolada de seu impulso constituinte (a promessa) (Chueiri, 2013).

A Constituição deve ser pressuposta como poder constituinte. Estaria aí sua força, especialmente a de uma Constituição radical, "na medida em que é a primeira ordem que se (auto) impõe como manifestação do poder constituinte e da soberania popular, comprometendo ambos" (Chueiri, 2013, p. 33). Poder constituinte e Constituição são, portanto, processos, lutas, reivindicações. Por isso, o primeiro não se esgota em uma data única (no caso da Constituição Federal de
1988, ele não corresponde a, apenas, o período entre fevereiro de 1987 e outubro de 1988). Ele se manifesta muito antes dos processos formais constituintes e se faz presente na própria Constituição.

Poder constituinte e poder constituído estabelecem uma dinâmica que possibilita a instauração e a manutenção de uma Constituição radical. Em outra perspectiva, esse movimento refere-se à capacidade de o povo autolegislar-se e fundar a ordem normativa que o governará. Porém, a potência desse ato não se esgota no ato formal de promulgação da Constituição. Ao se impor uma Constituição e, com isso, constituir-se como comunidade política, o povo exige, ao mesmo tempo, que tal Constituição seja vivida e experimentada (Chueiri, 2013).

Essa concepção de Constituição exige uma hermenêutica constitucional comprometida com a democratização da interpretação constitucional, visto que todo sujeito que vive a Constituição é seu legítimo intérprete, isto é, todo(a) aquele(a) que vive no contexto regulado por uma norma é um(a) intérprete dessa norma. Assim, estão vinculados a esse processo não apenas os julgadores e os procedimentos formalizados, mas todos os cidadãos, cidadãs, grupos sociais e potências públicas, participantes materiais de uma sociedade aberta dos intérpretes da Constituição e representantes de forças ativas de significação dos direitos (Haberle, 1997). A elaboração do significado dos direitos está ativamente associada às narrativas que situam e fornecem sentidos ao conjunto de instituições e de normas jurídicas. Essas narrativas estabelecem paradigmas para dinâmicas de obediência, consentimento, contradição e resistência (Cover, 2016).

Em termos de tensão entre poder constituinte e poder constituído, diferentes narrativas estiveram em disputa pela significação social do direito à educação e do acesso ao ensino superior durante o processo constituinte de 1987/88. Embora a narrativa do mérito individual tenha se tornado hegemônica, a linguagem dos direitos expressa pela CF/88 e o alargamento do círculo de seus intérpretes têm possibilitado novos campos semânticos para que os movimentos negro, de luta pelo direito à educação e estudantes de ensino médio público reivindiquem uma gramática jurídica compatível com as suas experiências sociais. 


\section{4}

\section{O processo constituinte de $1987 / 88$ e a conformação de sentidos para o direito à educação superior na Constituição Federal de 1988}

A Constituinte de 1987/88 foi antecedida por intensa mobilização popular, sendo um fenômeno histórico-social com consequências que transcendem a redação jurídico-constitucional das normas, tais como: emergência de movimentos e de organizações sociais, reconhecimento institucional a grupos alternativos ou marginais à ordem então vigente, inclusão de novos temas na agenda pública, mudanças no comportamento político de determinados setores sociais, construção de uma base sólida para o ideário democrático na sociedade e nas instituições e formação de novas forças políticas (Coelho, 2009).

A Assembleia Nacional Constituinte foi formada por Comissões Temáticas, cada uma compreendendo Subcomissões Temáticas. As Subcomissões Temáticas cuidaram de um tema ou subtema e elaboraram dispositivos a respeito deste; já as Comissões Temáticas ficaram encarregadas de formular um capítulo ou título a partir da agregação dos trabalhos das respectivas Subcomissões. A sistematização dos dispositivos aprovados pelas Comissões, a formulação do arcabouço de títulos e de capítulos e a elaboração do Projeto de Constituição ficaram a cargo da Comissão de Sistematização. Por fim, a discussão, a votação e a redação final do Projeto de Constituição consistiram em atribuições do Plenário da Assembleia Nacional Constituinte (Coelho, 2009).

O processo teve muitos impasses e momentos críticos, em que diferentes visões de sociedade e de Estado confrontaram-se intensamente. As audiências públicas nas Subcomissões Temáticas integraram uma das formas de participação da sociedade civil organizada e dos cidadãos e cidadãs. Diferentes atores sociais, como o movimento negro e de luta pelo direito à educação, irromperam na Constituinte $e$ nela encontraram oportunidade de participação e de expressão política (Coelho, 2009).

No âmbito da Subcomissão dos Negros, percebemos a existência de disputas entre duas visões de sociedade e de dever do Estado, uma marcada pelo mito da democracia racial e outra apontando para a necessi- dade de medidas legislativas e de políticas públicas específicas voltadas à população negra e ligadas a áreas como educação, saúde, previdência social e trabalho, tratadas pelas demais Subcomissões. $\mathrm{Na}$ audiência do dia 28 de abril de 1987, houve tensões entre parlamentares e militantes do movimento negro, com os primeiros questionando a dimensão que havia sido dada à questão étnico-racial, através do argumento da convivência harmônica entre negros e brancos no Brasil, e os demais contestando essa postura (Backes, Azevedo, 2009):

Eu me confesso surpreendido pela reunião. (...) Então, me parece que o aspecto dramático de segregação colocado aqui, talvez seja um aspecto geracional, de geração, ou um aspecto circunstancial, local, geográfico. (...) Me parece que, realmente, a democracia, em qualquer lugar do mundo, tem que ser pluriracial, porque existem muitas raças. A referência aos japoneses, eu até anotei aqui e comentava com o Sr. Presidente, a imigração japonesa foi estimulada no Estado do Paraná a ponto de nós termos lá, hoje, centenas de milhares de japoneses. E não estaria disposto a propiciar, a colaborar para que a nossa Constituição tivesse qualquer artigo que propiciasse o favorecimento a qualquer segmento racial. Nem ao negro, nem ao branco, nem ao amarelo, nem ao índio. Eu acho que a igualdade perante a lei é de absoluta justiça. Liberdade com igualdade. (...) A situação do negro no Brasil não é um problema de Constituição, é um problema de educação. (...) Mas a minha posição, hoje, como Relator, e eu posso modificá-la em relação ao que pensam os meus colegas constituintes, é essa: na Constituição, igualdade para todos. Não se pode privilegiar nenhum segmento, seja ele racial, seja ele político, seja de credo, qualquer segmento. Na lei ordinária, propiciar que a educação seja ampla, democrática, aberta, de acesso fácil a todas as pessoas e até algo mais, providenciando que os segmentos da sociedade organiza$d a$, universidades, os segmentos do ensino onde se detecte que haja uma predisposição para isso, a lei possa ser rigorosa, dando o direito desse acesso. (...) (Constituinte e Relator Alceni Guerra, na reunião do dia 28/04/1987).

O discurso do relator é estruturado em torno de uma concepção formal, abstrata e liberal de igualdade, 
que desconsidera as relações sociais desiguais entre os diversos grupos étnico-raciais, justificada a partir do mito da democracia racial. A identidade nacional brasileira foi construída a partir desse mito $^{6}$, que teve como condições históricas indispensáveis ao seu estabelecimento a Abolição da Escravidão em 1888 e a Proclamação da República em 1889, fatos que instituíram uma ordem jurídica formalmente livre e igualitária (Bernardino, 2002).

A construção do imaginário de uma nação mestiça, enquanto forma de sociabilidade que incluiria a totalidade dos indivíduos livres, foi intensificada pelo movimento abolicionista e se aprofundou durante o período republicano. Segundo esse pensamento, a liberdade, conquistada pela abolição da escravidão, transmuta-se imediatamente em igualdade e em cidadania, na ausência de preconceito e de discriminação racial. As desigualdades sociais remanescentes passam a se ancorar na ordem econômica e cultural das classes sociais (Guimarães, 2012).

O mito da democracia racial tem representado um campo discursivo autoritário, uma vez que se fecha completamente a qualquer realidade empírica de desigualdade estrutural de poder que requeira a implementação de políticas públicas voltadas à concretização de direitos de sujeitos pertencentes a grupos sociais específicos. Essa ideologia racial toma o racismo como manifestações de indivíduos e nega seu caráter institucional e estruturante das relações sociais brasileiras (Guimarães, 2015).

Por isso, em sua fala, o relator recusa-se a colaborar para que o projeto constitucional apresente algum artigo que favoreça qualquer segmento racial, apostando na justiça da "igualdade perante a lei". Refutando a tese de que a segregação seria um "aspecto geracional" ou um "aspecto circunstancial, local, geográfico", a denúncia do racismo e da discriminação racial e as lutas históricas dos(as) negros(as) pela igualdade aparecem nos discursos de militantes do movimento:

6 Esse mito ganhou sua elaboração acadêmica, através de sistematização e status científico para a época, por meio de Gilberto Freyre em sua obra Casa Grande \& Senzala (1933), que viria a moldar a imagem do Brasil. A tônica do texto é de otimismo em relação a um ambiente social gestado durante a fase colonial brasileira que favorece e é propício à ascensão social do mulato, tipo que tenderia a caracterizar o país num futuro próximo (Bernardino, 2002).
Desde as Constituições de 1934 e 1946, estão dizendo que todos somos iguais perante a lei. Nós queremos, sim, mecanismos de resgate que possam colocar o negro efetivamente numa situação de igualdade porque, até o presente momento, somos iguais perante a lei, mas quem somos nós? Somos as grandes populações dos presídios, da prostituição, da marginalização no mercado de trabaIho. Nós queremos, sim, que a Constituição crie mecanismos que propiciem um efetivo "começar" em condições de igualdade da comunidade negra neste País. (...) Nós não estamos aqui brincando de fazer Constituição. Não queremos essa lei abstrata e geral que, de repente, reproduz aquela história de que no Brasil não existe racismo, porque o negro reconhece o seu lugar. Nós queremos, efetivamente, que a lei crie estímulos fiscais para que a sociedade civil e o Estado tomem medidas concretas de significação compensatória, a fim de implementar aos brasileiros de ascendência africana o direito à isonomia nos setores de trabalho, remuneração, educação, justiça, moradia, saúde, e vai por aí afora (Lélia Gonzales, na reunião do dia 28/04/1987).

Em seu discurso, a feminista negra Lélia Gonzalez problematiza a dimensão formal da igualdade assegurada por Constituições brasileiras anteriores, apresentando contextos de subalternização da população negra e reivindicando "mecanismos de resgate" capazes de garantir uma situação de igualdade efetiva. Ela recusa uma dimensão abstrata e geral de legalidade, reprodutora do mito da democracia racial. Essas "medidas concretas de significação compensatória" deveriam ser criadas pela Constituição, a fim de que o Estado e a sociedade civil implementem o direito à isonomia aos brasileiros e às brasileiras de ascendência africana em diversos setores da vida social, a exemplo da educação.

Em audiência do dia 28 de maio de 1987, Lélia Gonzalez apresentou uma proposta de ações afirmativas na forma de dispositivos, contemplando sugestões esparsas dadas por outros participantes (Backes, Azevedo, 2009):

Todos são iguais perante à lei, que punirá, como crime inafiançável, qualquer discriminação atentatória aos direitos humanos. $\$ 1^{\circ}$ : Ninguém será prejudicado ou privilegiado, em razão de nascimento, raça, cor, sexo, estado civil, trabalho rural ou urba- 
no, religião, orientação sexual, convicções políticas ou filosóficas, de deficiência física ou mental, e qualquer particularidade. $\S 2^{\circ} \mathrm{O}$ poder público, mediante programas específicos, promoverá igualdade social, política, econômica e social. § $3^{\circ}$ Não constitui discriminação ou privilégio a aplicação de medidas compensatórias, visando a implementação do princípio constitucional da isonomia a pessoas pertencentes $a$, ou grupos historicamente discriminados.

Durante o processo constituinte, o espaço ocupado na Subcomissão dos Negros significou, para o movimento negro, um campo estratégico de denúncia do racismo e da farsa da democracia racial e de reivindicação por direitos e políticas públicas de seu interesse, como as ações afirmativas (Backes, Azevedo, 2009).

Essa reivindicação associa-se a um projeto político democratizante, construído desde os anos $1980 \mathrm{em}$ torno do alargamento da cidadania, da democracia e dos direitos sociais. A invenção, pelos movimentos sociais, de uma nova cidadania refere-se, dentre outras dimensões, à noção de direitos. Essa ideia é redefinida e tem como ponto de partida a concepção de um direito a ter direitos, que não se limita à implementação de direitos formais abstratos. Tal concepção inclui a invenção e a criação de novos direitos, que surgem de lutas específicas e de suas práticas concretas. A própria determinação do significado de direito e a afirmação de algum valor ou ideal como um direito são objetos de luta política (Dagnino, 2004).

A construção das universidades públicas brasileiras enquanto um direito vem sendo feita pelo movimento negro a partir da denúncia do relativo fechamento dessas instituições aos filhos e filhas das famílias negras mais pobres que, na concorrência em vestibulares, eram vencidos pelas classes brancas média e alta, frequentadoras dos colégios particulares de alto custo, que ofereciam um melhor treinamento para esse tipo de exame. A partir dos anos 1980, os jovens negros e pobres, descendentes dos escravizados africanos trazidos para o Brasil durante mais de trezentos anos de escravidão, passam a levantar a bandeira de luta por acesso às universidades (Guimarães, 2003).

Na Subcomissão da Educação, em reunião realizada no dia 18 de maio de 1987, o professor Moacir Gadot- ti ilustra esse histórico de elitização da universidade pública brasileira:

Não acredito que neste País haja condições de enfrentar o problema dos mais de oito milhões de crianças que estão sem acesso à escola, na idade chamada escolar, na atual Constituição, de 7 a 14 anos, e 52\% da população que não têm dois ou três anos de escolaridade. Isso não poderá ser enfrentado sem a atuação decisiva do Estado, e diria exclusiva do Estado, quer dizer, a escola pública é a única escola que pode ser a escola para todos. Enquanto existir essa divisão na sociedade brasileira, na escola brasileira, entre a escola pública e a escola privada, haverá sempre os que podem pagar e os que não podem pagar, justificando-se a idéia de que todos têm acesso, mas só têm acesso realmente os que podem pagar. Então, eu seria, e sou um militante dessa proposta de publicação geral da escola brasileira. (...) [A solução] passa nitidamente por uma defesa da escola pública, mas não só uma defesa de princípios, [mas também uma] defesa que crie mecanismos, desde [que] garanta a escola pública para todos. (...) A criação de um sistema nacional de escola pública, em que aqueles alunos que estão na escola pública desde o início, tenham o ensino superior garantido prioritariamente. Essa inversão do sistema educativo de que os alunos das escolas pagas, hoje, frequentam as universidades públicas, eu acho um crime na educação brasileira, é uma palavra pesada, mas acho um crime, porque é onde se verifica a discriminação; o pobre, que frequenta a escola pública, vai ter que depois pagar um ensino superior de baixa qualidade na maioria dos casos. Então, é um castigo para o aluno que frequenta a escola pública básica. Creio que, em uma legislação ordinária, isso deverá ser colocado, mas já se deveria ter alguma pista neste texto, para que o ensino superior público seja garantido prioritariamente àqueles que estão na escola pública básica, para criar um sistema nacional de educação pública.

Ele defende que o Estado brasileiro tem um papel central no enfrentamento das desigualdades educacionais e na garantia do direito à educação, uma vez que "a escola pública é a única escola que pode ser a escola para todos". Tece uma crítica à divisão da es- 
cola brasileira entre a escola pública e a privada, que distribui, de modo desigual, o acesso à educação entre "os que podem pagar e os que não podem pagar". Gadotti, ao defender a escola pública e ao se referir à importância de criação de um sistema nacional de educação pública, sustenta que o texto constitucional em construção tenha alguma diretriz que assegure, prioritariamente, o acesso ao ensino superior público pelos egressos de escolas públicas básicas.

O entendimento de Gadotti acerca do acesso ao ensino superior público é contrário à visão da Sociedade Brasileira para o Progresso da Ciência (SBPC), que defende o vestibular como a forma mais democrática de acesso à universidade, pois propiciaria um ingresso baseado no mérito (Barros, Andrés, 2009):

A Sociedade Brasileira para o Progresso da Ciência não endossa propostas de extinção dos concursos vestibulares. Conhecemos as experiências que se desenvolvem no mundo e sabemos que, apesar de todos os problemas, os concursos vestibulares constituem a maneira mais democrática, ainda, nas condições da sociedade que temos, de propiciar um acesso baseado no mérito. Claro que a nossa sociedade desigual faz com que o mérito seja, ainda, coincidente com as situações de classe. Isso será tão menor quanto mais o ensino público de $1^{\circ}$ e $2^{\circ}$ graus se desenvolva na quantidade, na velocidade e na qualidade que nós todos desejamos. Sabemos que a extinção dos concursos vestibulares e a substituição deles por um processo de mensuração do conhecimento dos estudantes - as notas - ao longo do $1^{\circ}$ e principalmente do $2^{\circ}$ grau, será, exclusivamente, uma maneira de reforçar o caráter apenas propedêutico do ensino de $1^{\circ}$ e $2^{\circ}$ graus, absolutamente antieducativo, antipedagógico, condenado em todo o mundo; e, em outros países, onde esse processo está sendo utilizado, já o estão abandonando em proveito da seleção via vestibular. O que não pode continuar acontecendo é que os concursos vestibulares sejam como foram há algum tempo atrás, em que o respondente passava a escolher determinadas alternativas, consideradas certas, para computar um certo número de pontos e, com isto, conseguir a sua vaga. Mas, isso diz respeito à maneira de se realizar o concurso vestibular, que, certamente, é de competência de leis que não têm a dignidade de uma Constituição e, até mesmo do âmbito interno de cada universidade (Luiz Antônio Cunha, na reunião do dia 23/04/1987).

Em seu discurso, o representante da SBPC reconhece a coincidência entre mérito individual e situação de classe social, não fazendo menção ao eixo étnico-racial que também estrutura desigualdades, o que aponta para a invisibilização da dimensão racializada do acesso ao ensino superior. Apesar desse reconhecimento, Luiz Antônio Cunha sustenta o caráter democrático dos vestibulares e a necessidade de desenvolvimento, em quantidade, velocidade e qualidade, do ensino público de $1^{\circ}$ e $2^{\circ}$ graus. A universidade continuaria reservada aos mais capazes e merecedores de estarem em seus espaços, através do critério de desempenho em exames vestibulares.

No decorrer do processo constituinte, o mito da democracia racial e da meritocracia foram adquirindo hegemonia. A definição de medidas compensatórias enquanto política pública de tratamento diferenciado voltada a grupos em situação de desigualdade e a explicitação de que sua adoção não significava discriminação ou privilégio gradativamente foram excluídas do texto constitucional a partir da etapa de sistematização (Quintans, 2015; Santos, 2015). A concepção de universidade como lugar cujo acesso está condicionado às capacidades individuais (princípio meritocrático) tornou-se hegemônica e impediu a constitucionalização das reivindicações por ações afirmativas na educação superior.

Os patamares de desempenho historicamente utilizados como parâmetro para o ingresso no ensino superior brasileiro sempre foram estipulados considerando-se, unicamente, o conhecimento mensurado no momento do exame vestibular, naturalizando-se performances que respondem mais a trajetórias sócio históricas e culturais ${ }^{7}$ do que a merecimentos in-

7 Pinto (2014) alerta para o risco existente em se buscar avaliar a capacidade dos(as) estudantes para o ingresso no ensino superior tendo por base apenas o seu desempenho em exames padronizados, como os vestibulares, visto que os resultados dessas provas sofrem forte influência do nível socioeconômico e cultural das famílias em que esses(as) estudantes estão inseridos(as), o que contribui com a naturalização e a perpetuação de uma ordem social extremamente injusta e desigual e reproduz as desigualdades no acesso à educação superior. 
dividuais isolados (Santos; Scopinho, 2016). O código universalista e liberal europeu, com as noções abstratas e formais de concurso/vestibular, de competição, de rendimento e de quantificação das trajetórias individuais, influenciou o meio social e acadêmico brasileiro de modo alienante e autoritário, pois silenciou o questionamento das práticas político-jurídicas sutis, sistemáticas e generalizadas de discriminação étnico-racial e socioeconômica. A ideologia do mérito, desvinculada de qualquer reflexão social, universalizou somente a concorrência, mas as condições para competir permaneceram desiguais (Carvalho, 2005).

Apesar da supressão de dispositivos envolvendo políticas afirmativas no texto constitucional, o processo constituinte de 1987/88 fortaleceu a inserção da temática étnico-racial na agenda política brasileira, visto que a $\mathrm{CF} / 88$ criminalizou o racismo e afirmou o princípio da igualdade e da não discriminação por cor/raça, conquistas do movimento negro que potencializaram lutas posteriores por ações afirmativas no ensino superior, expandindo o lugar das questões étnico-raciais para além do âmbito cultural e conferindo ao direito à educação o contorno de campo de disputa pela sua gramática (Santos, 2015).

A organização sociopolítica em torno da demanda por cotas desenvolveu-se em várias frentes, como a via do Legislativo e da ação interna de militância nas universidades. Os Núcleos de Estudos Afro-Brasileiros (NEAB's) e os cursos pré-vestibulares comunitários, por exemplo, pressionaram diversos órgãos administrativos universitários tanto pela adoção de políticas de cotas raciais, quanto de políticas de permanência dos(as) estudantes beneficiários(as) (Paiva, 2011).

Até 2012, as políticas de ação afirmativa foram criadas por resoluções internas das próprias universidades, no exercício de sua autonomia, ou por leis estaduais, efetuando-se de maneira totalmente descentralizada. Em julho de 2009, o partido político Democratas (DEM) propôs perante o Supremo Tribunal Federal (STF) uma ação judicial questionando a constitucionalidade de atos administrativos da Universidade de Brasília (UnB) que instituíram o programa de cotas raciais para ingressantes dos cursos de graduação e pedindo a declaração de inconstitucionalidade da política e a extensão da decisão a todos os programas dessa natureza no país (Feres Júnior, Daflon, Campos, 2010). Em abril de 2012, em sede da Arguição de Descumprimento de Preceito Fundamental (ADPF) n 186/2012 do Distrito Federal, o STF, por unanimidade dos votos dos ministros, declarou a constitucionalidade de cotas étnico-raciais para o acesso à educação superior no Brasil.

Esse julgamento impulsionou a promulgação da Lei $n^{\circ}$ 12.711, de 29 de agosto de 2012, chamada de Lei de Cotas, que prevê a reserva de vagas nas universidades federais e nas instituições federais de ensino técnico de nível médio para estudantes que tenham cursado integralmente o ensino médio em escolas públicas. No preenchimento dessas vagas, a Lei estabelece subcotas para candidatos oriundos de famílias com renda igual ou inferior a um salário mínimo e meio per capita e autodeclarados pretos, pardos, indígenas e pessoas com deficiência. Essa Lei operou no sentido de dar certa uniformidade à política de cotas em âmbito federal (Feres Júnior et al., 2013).

Confrontando o imaginário de uma sociedade brasileira racialmente harmônica e igualitária e o ideal do mérito e do esforço individuais enquanto critérios para o acesso às universidades públicas, a Lei de Cotas possibilitou a emergência de outra narrativa, em que as desigualdades verificadas nos resultados dos vestibulares estão fortemente vinculadas às histórias de grupos sociais marcadas por vulnerabilidades e privilégios de ordem étnico-racial e socioeconômica (Santos; Scopinho, 2016). Nos marcos de uma Constituição radical, a tensão entre poder constituído e constituinte tem sido a tensão entre o mito da democracia racial e da meritocracia e as políticas afirmativas de cotas.

\section{Percepções de estudantes de ensino médio de escola pública sobre vestibular, ações afirmativas, universidade pública e direito à educação}

Nossa aproximação com o campo da escola deu-se através do desenvolvimento de práticas de extensão universitária de educação popular em direitos, cujo objetivo era o de estimular e fortalecer os debates e as reflexões relativos à participação política, à cidadania e aos direitos fundamentais, a partir dos contextos escolares vividos pelos(as) estudantes. 
Faremos a apresentação e a discussão dos dados coletados através de entrevistas com os(as) estudantes e organizados em quatro categorias, de acordo com as percepções do(a) estudante sobre vestibular, ações afirmativas, universidade pública e direito à educação.

Na perspectiva de alargamento do círculo de intérpretes da Constituição, as falas desses estudantes demonstram o caráter tensional do discurso jurídico, uma vez que reivindicam condições para a efetivação da igualdade. Essas falas potencializam a interpretação da esfera do constituído ("capacidade individual") a partir de uma base social, vinculada às experiências reais e concretas dos sujeitos desse direito.

Vestibular

Os entrevistados e as entrevistadas percebem esse mecanismo de acesso à universidade em torno de dois eixos fundamentais: como instrumento produtor de exclusão e de segregação social, e como meio de avaliação do mérito e do esforço individuais, além de proporcionar ascensão profissional.

Ao falarem sobre a segregação e a exclusão produzidas pelo vestibular, os(as) estudantes destacaram sua dificuldade, complexidade e a desigualdade de condições entre quem frequentou escolas públicas e privadas ao longo da trajetória de vida e, principalmente, durante o ensino médio. Essa desigualdade de condições aparece associada à precariedade e à falta de qualidade do ensino oferecido em escolas públicas.

Ana nos forneceu alguns elementos para pensar o modo pelo qual o vestibular atua como um filtro socioeconômico que restringe o acesso de estudantes provenientes de camadas populares (Piotto, 2007). Segundo ela, os conteúdos básicos oferecidos pela escola pública não correspondem ao grau de especificidade exigido nas provas. Além disso, a falta de professores e de outras condições para "estudar por fora" dificulta o treinamento para o exame:

Então, é porque o ensino da escola pública, como eu estudei na escola pública desde a primeira série eu posso falar né, o ensino da escola pública ele é bem básico mesmo, ele é aquele básico, ele só, ele só te dá o conteúdo que você vai precisar saber assim, sabe? o básico mesmo. Então eu acho que como o vestibular, por ser mais complexo assim, eu acho que a gente ainda tem que estudar por fora, porque como o ensino público é base, então não tem como a gente fazer um vestibular assim, a não ser que a gente estude muito, assim, na escola, vai além, procure professores, porque na escola mesmo faltam muitos professores, falta, tem vezes que os alunos combinam todo mundo de ir embora e a gente fica sem aula, porque os professores se recusam a dar aula para um, dois alunos. Por esse motivo.

Tiago pensa que é importante a existência de um procedimento de seleção dos ingressantes em uma determinada instituição de ensino, mas considera que, dada a complexidade em se avaliar o potencial das pessoas, o vestibular acaba operando como uma ferramenta de segregação. A falta de condições para o oferecimento de um ensino de qualidade é uma crítica forte em sua fala:

Eu acho que o vestibular, de certa forma, é importante você ter um método de selecionar as pessoas que ingressam em uma determinada instituição de ensino, mas ao mesmo tempo ele é uma ferramenta que segrega as pessoas, na medida em que é difícil você determinar realmente quem tem potencial. Numa perspectiva acadêmica você consegue fazer isso, mas eu acho que não é o único fator importante para determinar quem deveria ingressar em uma universidade. Mas só que devido à situação limitada que a gente tem, eu acho que é difícil você pensar em uma outra forma de avaliar os estudantes para ingressar, que não seja o vestibular. (...) Eu acho que ele segrega... A proposta dele é que os alunos ingressem em uma universidade baseados em alguns conhecimentos que eles adquiriram no ensino médio. Só que para você levantar essa proposta, você precisa primeiro oferecer um ensino de qualidade e não é o que acontece. Como é que você pode falar para alguém o que ele deve saber se você não oferece as condições? É isso o que eu penso a respeito.

Ao tratar da inexistência ${ }^{8}$ de políticas de cotas na Fundação Universitária para o Vestibular (FUVEST),

8 No período de realização das entrevistas, entre abril e junho de 2016, a FUVEST ainda não havia instituído nenhuma política de cotas em seus exames vestibulares para ingresso na USP. 
o vestibular que tradicionalmente vem selecionando os ingressantes de graduação na Universidade de São Paulo (USP), João reflete sobre um ciclo em que a figura do Estado aparece diretamente implicada na reprodução das desigualdades educacionais. Ele relaciona esse ciclo à ideia de projeto de sociedade e de universidade fundado em lógicas de elitização:

Mas, assim, é importante dizer que, por exemplo, a USP, né, a FUVEST, né, o grande vestibular da FUVEST, nossa, muito excludente, né, a gente não vê cota para negro, cota para indígena, e nem para deficientes, entendeu? Então, assim, dá pra perceber aí que é uma escola, é um projeto, é um vestibular voltado para as pessoas da elite, entendeu? Porque as matérias em si, as questões, são para pessoas que fizeram todo o ensino médio, o ensino básico em escolas particulares, então, parece que é um ciclo, sabe, o Estado faz com que essa prova seja muito difícil, e garante para a gente que é nosso direito passar, que a gente tem que estar lá, mas, ao mesmo tempo, é uma coisa impossível na realidade, né, porque a gente não tem essa, todo esse contexto de ensino como alunos da elite, de escolas particulares têm.

De acordo com Carvalho (2005), a USP foi criada na década de 1930, seguindo uma trajetória de ausência de questionamentos acerca da exclusão socioeconômica e étnico-racial praticada no Brasil e se consolidando como uma instituição de peso destinada a ampliar a elite intelectual branca do país.

Outro eixo de percepção acerca do vestibular refere-se à sua atuação enquanto meio de avaliação do mérito e do esforço individuais, além de proporcionar ascensão profissional. Nesse sentido, consiste a fala de Dandara, para quem a dedicação e a vontade individuais são os elementos centrais e determinantes para o acesso à universidade:

O que eu penso sobre o vestibular? É uma estratégia em que muitos têm a possibilidade de... Se querer realmente, não basta falar assim: "ai, eu quero mas não vou fazer nada”, tem que querer e correr atrás, buscar o que quer. Para fazer, assim, as provas, (...) a pessoa, se ela quiser mesmo, buscar, ela consegue. É uma forma de adquirir um pouco mais de conheci- mento e ver que não é brincadeira, que é algo que, se querer, vai conseguir, vai ser alguém, vai ter o que falar no futuro para os filhos, para os netos, assim: "Eu consegui, por que que vocês não podem?”.

Kowarick (1976) desenvolve uma crítica a essa ideia de potencialidade individual enquanto fator determinante para o ingresso no ensino superior. $\mathrm{O}$ autor argumenta que a possibilidade de tomar o elevador educacional e subir aos patamares mais elevados do ensino decorre de vantagens socialmente atribuídas aos concorrentes no momento da partida. Assim, em grande medida, os detentores de determinados capitais econômicos e socioculturais serão os "favoritos", aqueles que poderão percorrer a trajetória educacional até os níveis mais elevados.

Os entrevistados e as entrevistadas tenderam a denunciar as condições desiguais entre quem frequentou escolas públicas e privadas para competir pelas vagas oferecidas nos exames vestibulares, através da crítica à precariedade do ensino público. A visão do vestibular como um instrumento de exclusão e de segregação social tornou-se recorrente.

\section{Ações afirmativas}

Parcela expressiva dos entrevistados e das entrevistadas construiu seus argumentos de modo a defender esse tipo de política, tendo em vista as desigualdades que conformam as oportunidades educacionais dos sujeitos.

Ana diz conhecer as cotas raciais e sociais, afirmando que, enquanto persistir o racismo no Brasil, essas políticas serão necessárias. Se, por um lado, as cotas facilitam o acesso de determinados grupos sociais à universidade, por outro, há reações negativas aos sujeitos beneficiários dessas políticas. Sua fala expressa certo medo do preconceito em ser beneficiária da política de cotas, visto que o ingresso no ensino superior por esse meio pode representar também um percurso de riscos, ao ter que enfrentar a rejeição do ambiente universitário:

Então, eu acho que, como eu estava conversando com uma colega de sala esses dias sobre isso, tem um lado positivo mas tem um lado negativo. Eu estava conversando com a colega de sala, ela falou assim, que no nosso país, como existe muito pre- 
conceito, as cotas ainda são necessárias, certo? E eu concordo com ela, porque a partir do momento em que não tiver nenhum preconceito, nenhuma diferença racial, nem social, aí as cotas não seriam uma, seriam só uma opção, assim, digamos. (...) 0 positivo é que facilita a entrada, o ingresso dos negros e os estudantes de escola pública na universidade e o lado negativo é que muitas pessoas levam para o lado preconceituoso, chega: "ah, você é cotista e tal".

Pedro declara seu posicionamento contrário às ações afirmativas, construindo seu argumento a partir da noção de poder da vontade humana e de capacidade que as pessoas têm de ir ao encontro dos seus objetivos. Na sua visão, as cotas seriam uma forma de discriminação, porque criariam diferenciações baseadas na cor da pele, através do oferecimento de recompensas que não se justificariam no presente, uma vez que o sofrimento social dos negros situar-se-ia no passado:

Eu sou totalmente contra isso, totalmente contra. Eu acho que, assim, as pessoas falam assim: "ah, os negros, os negros, eles, eles têm uma desvantagem perante os brancos, eles não têm uma capacidade em passar numa faculdade que nem os brancos." Mas da onde? Porque assim, cara, se você querer, você vai atrás. Porque eu acredito que tem apenas uma coisa: o poder da vontade humana. Se você quer e você vai atrás, porque quando você quer você vai atrás. Se você, hoje, quer um carro, o que você vai fazer? Você vai trabalhar pra ter o carro. Agora se você quer ter o diploma na USP, você vai ganhar conhecimento para ter aquele diploma. E as cotas, elas, é uma forma de discriminar isso, né? Ele pega, assim, o... Fala assim, só porque da cor dele, porque no passado ele sofreu, que agora, nos dias de hoje, ele vai ser, de certa forma, recompensado. Eu sou totalmente contra isso (...) Eu acho que as cotas são uma forma de discriminar, assim. Eu não sou a favor sobre as cotas, porque as cotas, elas discriminam mais ainda, porque as pessoas, elas querem igualdade, e eu não vejo igualdade nisso.

Sua argumentação sobre as cotas, próxima ao campo discursivo autoritário da democracia racial, estrutura-se numa concepção formal acerca da igualdade, em que os indivíduos, livres e iguais, teriam as condições, as potencialidades e a responsabilidade em alcançar os seus objetivos, o que tornaria a intervenção do Estado, por meio da instituição de políticas de ação afirmativa, discriminatória. O seu argumento não parece considerar o racismo implicado nas relações sociais e nas políticas das instituições educacionais.

\section{Universidade pública}

Algumas das percepções aparecem associadas à dificuldade e à competição para entrar, ao ingresso significando a realização de um sonho, à excelência do ensino e da pesquisa, ao conhecimento aprofundado e de qualidade do mundo e das tecnologias, e à sua relevância para quem não tem condições de pagar por uma faculdade privada. Danilo demonstra a sua indignação com o fato de a universidade pública não estar aberta à demanda dos estudantes de famílias necessitadas do ponto de vista socioeconômico. Sua fala dialoga com a reivindicação do professor Moacir Gadotti no processo constituinte de $1987 / 88$, para quem o acesso à universidade pública deveria ser assegurado, prioritariamente, aos egressos de escolas públicas:

Então, eu gostaria de destacar, os alunos das escolas particulares que querem ingressar na universidade pública, isso eu acho assim que é uma coisa absurda, porque se a pessoa, ela está numa escola particular, é porque ela realmente tem condições de pagar. Não digo quem ganhou bolsa, mas, assim, aqueles que têm realmente condições de pagar, eu acho que eles deveriam ingressar numa faculdade particular e deixar a faculdade pública para quem não tem dinheiro, para quem realmente precisa. Eu acho que isso seria uma coisa primordial que acontecesse.

Ana destaca que o caráter público da universidade precisa estar vinculado a um acesso mais democrático, utilizando, em sua fala, a comparação com a escola pública. Para ela, embora a universidade seja pública, trata-se de um bem de certo modo privatizado, uma vez que é restrito a determinados grupos sociais e difícil de ser alcançado por outros:

De uma forma geral, eu penso assim que a universidade pública é uma melhor opção para muitas pessoas, né? Só que o que eu acho é que a universidade pública deveria ser como a escola pública, não assim no lado negativo, sabe? É porque, tipo, eu 
não sei explicar muito bem, mas, assim, porque na escola pública, as pessoas têm mais acesso, sabe? É meio muito privado, é um pouco privado, assim, sabe? (...) Enfim, é um pouco privado, sabe? Muita gente, para conseguir entrar na universidade pública tem que estudar muito, principalmente um aluno de escola pública, que é mais complicado, porque uma escola particular tem muito mais recursos, muito mais qualidade, né? E, é isso o que eu acho. (...) É uma coisa mais difícil de alcançar, digamos.

Sua fala expressa a precarização do setor público operada por décadas de políticas neoliberais, em que a escola pública aparece associada à baixa qualidade e à ineficiência e a privada à boa qualidade e à eficiência. Esse imaginário fortalece o distanciamento do horizonte dos(as) estudantes de camadas populares do acesso à educação superior pública de qualidade, uma vez que enxergam esse espaço destinado àqueles com maiores chances de serem aprovados em vestibulares, porque puderam frequentar, graças às suas possibilidades econômicas, escolas privadas.

João, que frequentou o ambiente universitário ao estudar em um cursinho popular preparatório para o vestibular, enfatiza, em sua fala, contradições presentes no cotidiano da universidade pública: ao mesmo tempo em que é palco de ações políticas protagonizadas por coletivos, a instituição vivencia atos de racismo e de homofobia. Para ele, as diversidades atuantes politicamente no ambiente acadêmico causam incômodo às categorias sociais detentoras de privilégios. Do sentimento de opressão e da necessidade de compartilhamento de experiências nasce a ação política:

Bom, eu acho que a universidade pública atualmente é um palco para bastantes discussões a respeito de movimentos, sabe? De ações, tipo assim, coletivas. Por exemplo, a gente pode falar dos coletivos negros, dos coletivos LGBT's, de vários outros coletivos que, assim, agem politicamente no atual cenário brasileiro, entendeu? Entretanto, a gente vê também um contraste, né, propriamente dentro das universidades, a gente vê atos de racismo, atos de homofobia. Então, assim, é uma coisa assim muito paradoxal, né, ao mesmo tempo em que alunos de escola, ao mesmo tempo em que alunos da faculdade se juntam para mudar alguma rea- lidade, eles se chocam também... (...) Eu acho que é importante a gente falar que a universidade é um ambiente, assim, composto por pessoas de diversas cidades, de diversas subculturas dentro do Brasil, de diversas condições socioeconômicas, né? Então, por exemplo, uma pessoa branca, da elite, que nunca, por exemplo, sofreu racismo, não tem por que ela se juntar às pessoas do coletivo negro, entendeu? E, muitas vezes, quando [do coletivo negro] tomam, às vezes, aulas, ou, sei lá, fazem [atos] dentro da própria faculdade, essas pessoas da elite que eu acabei de dizer, se sentem incomodadas, né, porque elas não querem ver ninguém, como que fala, ativamente político ali, sabe, eles querem estudar e serem ricos e... Eles não têm necessidade desses movimentos. Entretanto, é importante dizer que, por exemplo, da parcela de homossexuais nas universidades, eles sofrem sim preconceito diariamente, entendeu? Assim como as pessoas trans, enfim... Então, elas [pessoas] se juntam, né... Eu acho que a gente se junta quando a gente é oprimido, a gente vê alguém que também está oprimido, a gente se junta, é uma coisa assim importante. A gente se junta para se sentir melhor. Daí que surgem os movimentos, entendeu?

Embora a universidade se apresente como um ambiente hostil a diferentes grupos sociais oprimidos, a fala de João destaca as manifestações de resistência engendradas no interior do mundo acadêmico, que buscam questionar o status quo e as relações de privilégio.

\section{Direito à educação}

As tônicas da igualdade e da qualidade do ensino estiveram presentes nas falas de alguns e de algumas estudantes. Danilo entende o direito ao estudo como elemento central para o crescimento profissional e para a melhora das condições de vida. Ele se refere à figura dos pais, a quem foi negado o direito à educação, pela necessidade de trabalharem para o sustento da família. Na sua visão, a construção da educação enquanto um direito é condição essencial para o acesso das classes sociais baixas:

Bom, direito à educação eu acho que é algo primordial que todo mundo tem que ter. Hoje em dia todo mundo tem que ter um direito a um estudo. Como, por exemplo, meus pais, eles não tiveram 
um direito ao estudo, eles não puderam estudar, não porque eles não quiseram, porque eles tiveram que trabalhar. E hoje em dia eu acho que isso tem que ser primordial, o estudo, porque sem o estudo as pessoas não são nada. Hoje o estudo é muito cobrado nos serviços, para você poder conseguir um cargo melhor, para você conseguir uma qualificação melhor, você tem que estudar. E se não tivesse direito ao estudo, seria basicamente difícil para quem é da classe baixa ter acesso à educação. Isso eu acho que é uma coisa boa.

Tiago percebe o direito à educação inserido no campo dos direitos fundamentais, por meio dos quais a cidadania e a democracia se concretizam. À figura do Estado ele atribui o dever de garantir uma formação cultural, intelectual e profissional para todos e todas, visto que a igualdade é um princípio diretamente associado à noção de cidadania:

Nós vivemos em uma democracia. Para que as pessoas consigam exercer a sua democracia, elas precisam, existem alguns direitos fundamentais que elas precisam ter, um deles é a educação, porque ela permite que você se afirme como cidadão, como indivíduo participante de uma sociedade. $E$ pra isso você precisa ter uma certa formação cultural, intelectual e profissional e isso necessita de ser garantido a você, através do Estado, que seja. Então eu acho que é um direito importante, uma vez que nós somos cidadãos ditos iguais.

Dandara também associa o direito à educação à ideia de igualdade. No entanto, segundo ela, a falta de uma educação antirracista e anti-homofóbica nas escolas favorece a desistência de estudantes negros e homossexuais, o que contraria o pressuposto de igualdade. Sua fala estabelece uma correspondência entre o direito à educação e o merecimento de estar na faculdade:

É, igualdade a todos, assim, a gente, hoje em dia, tem acesso à escola pública, mas, por falta, assim, de instrução, muitos acabam desistindo, como preconceito, preconceito contra negros, contra homossexuais. Eu... Por não ensinar que deve ser respeitado, que é algo que por mais que a pessoa não aceita o que faz ou a raça, ela está assim, é igual a mim, só muda a cor, só muda o que gosta. Então isso é algo que deve mudar... Mas pelo direito à educação todos merecem estar na faculdade, quando querem, merecem estar na faculdade.

Ela reconhece que nem todos conseguem chegar ao ensino superior, uma vez que, no ambiente escolar, o racismo atua de modo a distribuir de modo desigual as oportunidades educacionais:

Porque muitos fazem as provas, por mais que tirem nota baixa, eles podem até continuar tentando, tal, mas nem todos conseguem chegar lá. Como hoje em dia vê-se numa sala de aula os alunos... Por exemplo, aqui, pode ter 50 brancos e 10 negros, então, a igualdade está totalmente baixa. Praticamente as raças mais claras estão tendo mais oportunidades para chegar aonde querem e as mais escuras não estão tendo.

No entanto, a fala de Dandara também é marcada por certas ambiguidades. Ao mesmo tempo em que acredita na justiça dos exames seletivos e da avaliação do esforço e do empenho individuais em contextos de elitização do acesso à escola, ela também aponta para o racismo presente em alguns concursos:

As provas são justas, porque são para aqueles que buscam, que estudam verdadeiramente. Mas em muitos concursos, se a pessoa colocar lá que é negro, não vai pra frente, em muitos casos não vai pra frente. (...) As pessoas conseguem, sim, fazer, tirar notas boas, mas se tiver esforço. (...) Mas quando a pessoa quer de verdade... Igual antigamente, as pessoas não tinham muito acesso à escola como hoje, não tinham muito mas muitos se tornavam médicos, engenheiros, porque por mais que não tinham muito acesso, eles batalhavam, eles não ouviam pelo que as pessoas falavam ou eles deixavam: "isso não faz parte de mim, eu quero é isso". Então, basta o querer. Esse é o meu ponto de vista.

Quando constrói a sua percepção sobre direito à educação, Carlos associa o período de crise econômica à dificuldade de ingressar em uma faculdade, o que pode estar relacionado ao pagamento de mensalidades em instituições privadas enquanto horizonte de acesso à educação superior: 
Por exemplo, agora que a gente está em crise, chega até ser um pouco mais difícil entrar em faculdade, devido às vagas que parecem que diminuem, devido a gastos e etc. Então eu acho que está, está a meio termo ainda essa, essa questão. (...) Direito à educação também até, às vezes a cor, também, a etnia prejudica às vezes ou às vezes também até ajuda, mas também meio que depende... (...) Geralmente, um pouco mais atrás, eram os brancos, a etnia branca que entrava em mais faculdade e tal. Mas agora está, está melhorando, já não tem mais esse tanto, esse, como se diz, o preconceito mais. (...) As várias lutas, né, que os próprios negros e etc. fizeram estão, estão, como se diz, evoluindo e está começando a entrar dentro da cabeça das pessoas, por isso. (...) Que não, que não acreditavam que, por exemplo, um negro tinha o mesmo potencial que um branco. Era mais ou menos isso.

Ele afirma que a efetividade desse direito é relativa, visto que considera, no contexto das relações sociais, dinâmicas relacionadas à segregação socioeconômica e étnico-racial. Sua fala aponta para as conquistas recentes do movimento negro em termos de democratização do ensino superior.

\section{Considerações finais}

Nosso olhar voltou-se para alguns dos processos sociopolíticos recentes de democratização do Estado e da sociedade brasileira, com foco nas reivindicações do movimento negro e de outros atores sociais por políticas de cotas nas instituições públicas de educação superior.

Após tensões e disputas na Constituinte de 1987/88 entre o discurso da democracia racial e da meritocracia e as demandas por ações afirmativas nas universidades, o texto final da Constituição Federal dispôs que "o dever do Estado com a educação será efetivado mediante a garantia de acesso aos níveis mais elevados do ensino, da pesquisa e da criação artística, segundo a capacidade de cada um" (artigo 208, inciso V). 0 critério meritocrático afirmado legalmente não refletiu a potência democratizante das reivindicações populares, bem como invisibilizou a dimensão racializada do acesso à educação superior no Brasil.

Enquanto na Constituinte de 1987/88, a concepção de "capacidades individuais" esteve associada a uma dimensão intelectual/cognitiva, vinculada à apreensão de conhecimentos adquiridos previamente, entre os estudantes entrevistados por nós tal concepção aparece fortemente ligada a uma diferenciação socioeconômica entre classes sociais, entre aqueles que conseguiram ou não pagar para frequentar uma escola privada e ter acesso aos capitais culturais necessários à aprovação no vestibular. Desse modo, a cota também pode representar para esses sujeitos mais uma faceta da discriminação, ao ingressarem em um ambiente universitário elitizado.

Ao longo da história brasileira, o acesso restrito à educação tem sido um marcador no exercício dos direitos e da cidadania, visto que a proibição do voto aos analfabetos somente será superada pela Constituição de 1988 (Vieira, 2007). Em muitos aspectos, essa Constituição garante um acesso mais amplo e universal à educação. Contudo, no caso do ensino superior, a hegemonia do mito da democracia racial e da meritocracia enfraqueceu o seu potencial democratizante da universidade.

As lutas do movimento negro pela democratização do ensino superior público remontam a décadas muito anteriores ao processo constituinte de 1987/88 e se mostraram bastante ativas nos anos 1990, em defesa das cotas raciais, ancoradas na linguagem dos direitos expressa pela Constituição de 1988. Ao fortalecer essa agenda na educação superior, lugar historicamente reservado às camadas sociais dominantes ditas mais "capazes", o movimento negro tem evidenciado o racismo institucional e reivindicado a todo tempo e de todas as formas, a construção de uma sociedade mais justa e igualitária.

O julgamento da ADPF $n^{\circ} 186$ pelo STF e a promulgação da Lei de Cotas, em 2012, possibilitaram a emergência, no campo jurídico-normativo, de outras narrativas capazes de legitimar o acesso à universidade brasileira, silenciadas na Constituinte de 1987/88 e reelaboradas à luz dos princípios constitucionais que fundamentam a construção de um Estado democrático. A potência (constituinte) do texto constitucional de 1988 tem sido mobilizada pela ação dos atores sociais no sentido da transformação radical do direito (constituído) moderno, de matriz liberal, individualista, formal e abstrata. 


\section{Referências}

Backes, A. L.; Azevedo, D. B. de (2009). Subcomissão dos Negros, Populações Indígenas, Pessoas Deficientes e Minorias. In: Ana Luiza Backes, Débora Bithiah de Azevedo e José Cordeiro de Araújo (Org.), Audiências públicas na Assembleia Nacional Constituinte: a sociedade na tribuna. Brasília: Câmara dos Deputados, Edições Câmara.

Barros, H. H. D. de; Andrés, A. (2009). Subcomissão da Educação, Cultura e Esportes. In: Ana Luiza Backes, Débora Bithiah de Azevedo e José Cordeiro de Araújo (Org.), Audiências públicas na Assembleia Nacional Constituinte: a sociedade na tribuna. Brasília: Câmara dos Deputados, Edições Câmara.

Bernardino, J. (2002). Ação Afirmativa e a Rediscussão do Mito da Democracia Racial no Brasil. Revista Estudos Afro-Asiáticos, Ano 24, n ${ }^{\circ}$, pp. 247-273. BRASIL. Assembleia Nacional Constituinte (Atas de Comissões). Subcomissão da Educação, Cultura e Esportes. Disponivel em: <http://www.senado. gov.br/publicacoes/anais/asp/CT_Abertura.asp>. Acesso em 25 de dez. de 2015.

. Assembleia Nacional Constituinte (Atas de Comissões). Subcomissão dos Negros, Populações Indígenas, Pessoas Deficientes e Minorias. Disponivel em: <http://www.senado.gov.br/publicacoes/anais/asp/CT_Abertura.asp>. Acesso em 25 de dez. de 2015.

Constituição da República Federativa do Brasil de 1988. Disponível em: <http://www.planalto.gov.br/ccivil_03/Constituicao/Constituicao. htm>. Acesso em 28 de out. de 2017.

Lei $n^{\circ} 9.394$, de 20 de dezembro de 1996. Estabelece as diretrizes e bases da educação nacional. Disponível em: <http://www.planalto.gov. br/ccivil_03/leis/L9394.htm>. Acesso em 28 de out. de 2017.

. Lei $n^{\circ} 12.711$, de 29 de agosto de 2012. Dispõe sobre o ingresso nas universidades federais e nas instituições federais de ensino técnico de nível médio e dá outras providências. Disponível em: <http://www.planalto.gov.br/CCIVIL_03/_ Ato2011-2014/2012/Lei/L12711.htm>. Acesso em 28 de out. de 2017.

Carvalho, J. J. de (2005). Inclusão étnica e racial no Brasil: a questão das cotas no ensino superior. São Paulo: Attar Editorial.
Chueiri, V. K. de (2013). Constituição radical: uma ideia e uma prática. Revista da Faculdade de Direito da UFPR, Curitiba, $\mathrm{n}^{\circ} 58$, pp. 25-36.

Coelho, J. G. L. (2009). Processo Constituinte, Audiências Públicas e o nascimento de uma nova ordem. In: Ana Luiza Backes, Débora Bithiah de Azevedo e José Cordeiro de Araújo (Org.), Audiências públicas na Assembleia Nacional Constituinte: a sociedade na tribuna. Brasília: Câmara dos Deputados, Edições Câmara.

Cover, R. M. (2016). Nomos e narração. Tradução de Luis Rosenfield. Anamorphosis - Revista Internacional de Direito e Literatura, vol. 2, n 2, pp. 187-268.

Dagnino, E. (2004). ¿Sociedade civil, participação e cidadania: de que estamos falando? In: Daniel Mato (Org.), Políticas de ciudadanía y sociedad civil em tiempos de globalización. Caracas: FACES, Universidad Central de Venezuela, pp. 95-110.

Feres Júnior, J.; Daflon, V. T. (2014). Políticas da Igualdade Racial no Ensino Superior. Cadernos do Desenvolvimento Fluminense, $n^{\circ}$ 5, pp. 31-44.

Feres Júnior, J.; Daflon, V. T.; Campos, L. A. (2010). Cotas no STF: os argumentos como eles são. Insight Inteligência, pp. 124-136.

Feres Júnior, J.; Daflon, V.; Ramos, P.; Miguel, L. (2013). $\mathrm{O}$ impacto da Lei $\mathrm{n}^{\circ} 12.711$ sobre as universidades federais. Levantamento das políticas de ação afirmativa (GEMAA), IESP-UERJ, pp. 1-34.

Guimarães, A. S. A. (2015). Ação afirmativa, autoritarismo e liberalismo no Brasil de 1968. Novos Estudos CEBRAP 101, pp. 5-25.

(2012). Cidadania e retóricas negras de inclusão social. Dossiê Questão Racial no Brasil. Revista de Cultura e Política Lua Nova, São Paulo, nº 85, pp. 13-40.

(2003). O acesso de negros às universidades públicas. In: Petronilha Beatriz Gonçalves e Silva e Valter Roberto Silvério (Org.), Educação e ações afirmativas: entre a injustiça simbólica e a injustiça econômica. Brasília: Instituto Nacional de Estudos e Pesquisas Educacionais Anísio Teixeira.

Haberle, P. (1997). Hermenêutica Constitucional. A sociedade aberta dos intérpretes da Constituição: contribuição para a interpretação pluralista e "procedimental" da Constituição. Porto Alegre: Sergio Antonio Fabris Editor. 
Kowarick, L. (1976). Os favoritos: a corrida rumo à Universidade. Revista Ciência e Cultura, São Paulo, vol. 28, n² 2, pp. 133-138.

Paiva, A. R. (2011). Movimentos sociais e políticas de ação afirmativa nas universidades brasileiras: a ação do movimento negro. In: Ilse Scherer-Warren e Lígia Helena Hahn Luchmann (Org.), Movimentos sociais e participação: abordagens e experiências no Brasil e na América Latina. Florianópolis: Ed. da UFSC.

Pinto, J. M. de R. (2014). Dinheiro traz felicidade? A relação entre insumos e qualidade na educação. Arquivos Analíticos de Políticas Educativas, vol. 22, $\mathrm{n}^{\circ} 19$.

(2003). Introdução. In: Petroni-

Iha Beatriz Gonçalves e Silva e Valter Roberto Silvério (Org.), Educação e ações afirmativas: entre a injustiça simbólica e a injustiça econômica. Brasília: Instituto Nacional de Estudos e Pesquisas Educacionais Anísio Teixeira.

(2004). O acesso à educação superior no Brasil. Educação \& Sociedade, Campinas, vol. 25, nº 88, pp. 727-756.

Piotto, D. C. (2007). As exceções e suas regras: estudantes das camadas populares em uma universidade pública. Tese (doutorado). São Paulo: Instituto de Psicologia da Universidade de São Paulo.

Quintans, M. T. D. (2015). Classe, raça e gênero na luta por direitos do movimento negro. Revista InSURgência do Instituto de Pesquisa em Direitos e Movimentos Sociais (IPDMS), Brasília, ano 1, vol. 1, $\mathrm{n}^{\circ} 1$.

Rodriguez, J. R. (2013). A desintegração do status quo: Direito e lutas sociais. Dossiê: 25 anos da Constituição de 1988. Novos Estudos CEBRAP 96, pp. 49-66.

Santos, E. F. dos; Scopinho, R. A. (2016). Desigualdades raciais, mérito e excelência acadêmica: representações sociais em disputa. Psicologia: Ciência e Profissão, vol. 36, n² 2, pp. 267-279.

Santos, N. N. da S. (2015). A voz e a palavra do movimento negro na Assembleia Nacional Constituinte (1987/1988): um estudo das demandas por direitos. Dissertação (mestrado). São Paulo: Escola de Direito de São Paulo da Fundação Getúlio Vargas.

Triviños, A. N. S. (2011). Introdução à Pesquisa em Ciências Sociais: a pesquisa qualitativa em educação. São Paulo: Atlas.

Vieira, S. L. (2007). A educação nas Constituições brasileiras: texto e contexto. Revista Brasileira de Estudos Pedagógicos (RBEP), Brasília, vol. 88, n² 219, pp. 291-309.
Data de submissão/Submission date: 27.01.2018.

Data de aceitação para publicação/Acceptance date: 16.10.2018. 